\title{
Study of incidence, trends and determinants of caesarean section in tertiary care hospital of Rajasthan, India
}

\author{
Neelam Sharma ${ }^{1}$, Anshul Jhanwar ${ }^{2 *}$ \\ ${ }^{1}$ Department of Obstetrics and Gynecology, ${ }^{2}$ Department of Pharmacology, Jhalawar Medical College, Jhalawar, \\ Rajasthan, India
}

Received: 06 June 2018

Revised: 11 June 2018

Accepted: 13 June 2018

*Correspondence:

Dr. Anshul Jhanwar,

E-mail: dranshul123@gmail.com

Copyright: ( $\odot$ the author(s), publisher and licensee Medip Academy. This is an open-access article distributed under the terms of the Creative Commons Attribution Non-Commercial License, which permits unrestricted non-commercial use, distribution, and reproduction in any medium, provided the original work is properly cited.

\section{ABSTRACT}

Background: Lower Segment Caesarean section (LSCS) is recommended when vaginal delivery might pose a risk to the mother or baby. Worldwide rise in LSCS rate during the last three decades, has been the cause of alarm and needs an in-depth study.

Methods: It was a retrospective, observational study conducted in Obstetrics and Gynecology department of Jhalawar medical college, Jhalawar. Data were obtained from medical record database of patients admitted for deliveries from October 2017 to March 2018 over period of six months. The total number of patients delivered and the number of LSCS done were counted to find the incidence of LSCS in our hospital. Age, parity and gestational age of the patients who underwent LSCS were tabulated.

Results: In present study the incidence of LSCS was $31.1 \%$. Of these cases $91 \%$ belonged to age group $20-29$ yrs. Emergency LSCS $(72.1 \%)$ and primary LSCS $(66.5 \%)$ were more common. The commonest indication of LSCS was previous LSCS in 35\% followed by foetal distress, breech presentation, severe oligohydrominos and pre-eclampsia.

Conclusions: In present study LSCS rate was high as compared to the WHO standard. The scheme like Janani Suraksha Yojana (JSY) may have a great impact on accepting institutional deliveries by poor women which may be a reason of the increase of LSCS in India. Utilization of antenatal care, better doctor patient communication, doctor's commitment to reduce the rate of LSCS, may help to reduce the increasing rate of caesarean delivery.

Keywords: Gestational age, Lower segment caesarean section, Vaginal births

\section{INTRODUCTION}

Lower Segment Caesarean Section (LSCS) is the most commonly performed obstetric operation worldwide. With advent of modern anaesthesia, availability of improvised surgical techniques and prophylactic antibiotics, caesarean section has become a relatively safe and common procedure.

At present there is no strictly defined protocols for the indication of LSCS in our country. Caesarean section is usually performed to ensure safety of the mother and child under conditions of obstetric risks. This medical intervention is more or less justified under certain circumstances such as breech presentation, dystocia, previous caesarean section and suspected fetal compromise. The WHO published guidelines regarding Caesarean Section rates in 1985 which was revised in $1994 .^{1}$

The guidelines published in 1997 by UNICEF, WHO and UNFPA states that proportion of Caesarean births should 
range between 5 to $15 \%$. The rate of Caesarean Sections below 5\% seems to be associated with gaps in obstetric care leading to poor health outcomes for mothers and child, whereas rates over $15 \%$ don't seem to improve either maternal or infant health. ${ }^{2,3}$

In India the rural-urban difference between LSCS rates is quite conspicuous. The rate of LSCS is higher in urban areas than their rural counterparts for all the states. ${ }^{4}$

The rural-urban gap is relatively low in the states of Haryana, Delhi, Arunachal Pradesh and Kerala (below 5 percentage points). On the other hand, the gap is very high in the states of Jammu and Kashmir, West Bengal and Tripura (above 20 percentage points).

The higher urban rates may be a reflection of combination of factors like higher availability and utilization of maternal health care services, larger concentration of private health institutions in the cities and towns etc. Moreover, the demographic and socioeconomic backgrounds of the persons living in the rural and urban places affect the CS rate to a great extent. $^{5}$

Caesarean section is the second commonest surgery performed on women in India after tubectomy operation. In India giving birth on an auspicious day is driving women to go for caesarean on request. The present study was an effort to determine the incidence of LSCS and evaluate the indications in the Dept. of Obstetrics and Gynecology in Jhalawar Medical College, Jhalawar, Rajasthan. This is also a step to find if any of these indications can be revaluated to bring down the LSCS rate in the country to a level close to the standard set by WHO.

\section{METHODS}

This study was carried out in the Obstetrics and Gynecology Department of Jhalawar medical college (J.M.C.), Jhalawar, from October 2017 to March 2018. J.M.C. is a tertiary care centre having a large number of referral cases (unbooked patients) from city as well as from periphery and provides antenatal care and delivery services to low and high risk booked pregnant women.

Technically, booked mothers were defined as those who had at least three antenatal visits at our center while unbooked mothers included those who had no or less than three prenatal care visits during their whole pregnancy at our center and those who were referred in emergencies from other medical centers and hospitals.

During this period the total number of deliveries were counted and out of these the patients who underwent LSCS were selected. The indications for LSCS in these cases were noted along with the age of the patient, parity, weeks of gestation,situation and were analyzed. As the study was descriptive observational so no statistical analysis was needed.

\section{Inclusion criteria}

All booked as well as unbooked cases visited for delivery.

\section{Exclusion criteria}

- Cases with incomplete data.

- Cases with medical problems like thyroid disorders, diabetes, hypertensive disorders and other heart disease

- Estimated fetal weight more than $4 \mathrm{~kg}$ by ultrasonography.

\section{RESULTS}

A total of 4636 deliveries occurred during the study period. Of these $31.1 \%$ cases underwent LSCS while in $68.9 \%$ vaginal delivery was done as shown in Table 1.

Table 1: Type of deliveries.

\begin{tabular}{|lll|}
\hline Type of delivery & $\begin{array}{l}\text { Number of } \\
\text { cases (n) }\end{array}$ & Percent \\
\hline Caesarian section (LSCS) & 1440 & 31.1 \\
\hline Vaginal delivery & 3196 & 68.9 \\
\hline
\end{tabular}

Out of 1440 LSCS cases, $66.5 \%$ patients underwent Primary LSCS whereas in $33.5 \%$ of cases Repeat LSCS done as shown in Table 2. In repeat LSCS previous one LSCS were more common than previous two.

Table 2: Type of caesarean section.

\begin{tabular}{|lll|}
\hline $\begin{array}{l}\text { Type of caesarean } \\
\text { section }\end{array}$ & $\begin{array}{l}\text { Number of } \\
\text { cases (n) }\end{array}$ & Percentage \\
\hline Repeat caesarean section & 483 & 33.5 \\
\hline Primary caesarean section & 957 & 66.5 \\
\hline
\end{tabular}

Cases underwent LSCS were mainly in the age group of $25-29$ years $(48 \%)$ followed by $20-24$ years $(43 \%) .4 \%$ cases were in age group $<20$ years whereas few secondary infertility treated cases were of age $>35$ years as seen in Table 3 .

\section{Table 3: Distribution of LSCS according to} age groups.

\begin{tabular}{|lll|}
\hline Age in years & Number of cases (n) & Percentage \\
\hline$<20 y r s$ & 58 & 4 \\
\hline $20-24$ yrs & 620 & 43 \\
\hline $25-29 y r s$ & 693 & 48 \\
\hline $30-34 y r s$ & 54 & 3.8 \\
\hline $35-39 y r s$ & 13 & 1.9 \\
\hline $40-44 y r s$ & 02 & 0.14 \\
\hline Total & 1440 & 100 \\
\hline
\end{tabular}


Table 4: Distribution according to indication of LSCS.

\begin{tabular}{|lll|}
\hline Indication for LSCS & $\begin{array}{l}\text { Number of } \\
\text { cases (n) }\end{array}$ & Percentage \\
\hline Previous LSCS & 503 & 35 \\
\hline Foetal distress & 188 & 13 \\
\hline Breech presentation & 135 & 9.4 \\
\hline $\begin{array}{l}\text { IUGR, severe } \\
\text { Oligohydrominos }\end{array}$ & 126 & 8.8 \\
\hline $\begin{array}{l}\text { Eclampsia/pre-eclampsia } \\
\text { Cephalo pelvic } \\
\text { disproportion (CPD) }\end{array}$ & 118 & 8.2 \\
\hline obstructed labour & 97 & 6.7 \\
\hline $\begin{array}{l}\text { Failed induction } \\
\text { Placenta previa/abruptio } \\
\text { placenta }\end{array}$ & 82 & 5.7 \\
\hline $\begin{array}{l}\text { Bad obstetric history } \\
\text { (BOH)/treated for infertility }\end{array}$ & 27 & 4.3 \\
\hline $\begin{array}{l}\text { Premature rupture of } \\
\text { membrane }\end{array}$ & 25 & 4 \\
\hline On request & 19 & 1.9 \\
\hline
\end{tabular}

Previous LSCS $(35 \%)$ was the most common indication for LSCS followed by foetal distress (13\%) Breech presentation $(9.4 \%)$ and severe Oligohydrominos. Eclampsia was seen in $8.2 \%$ cases. Severe eclampsia with unfavourable cervix at $<30$ week gestation, Recurrent seizures refractory to medical management, Refractory severe hypertension $>160 / 110 \mathrm{~mm}$ of $\mathrm{Hg}$, maternal or foetal deterioration without impending delivery are usually the patients requiring a surgical interference.CPD is seen in $6.7 \%$ of cases. Not all the cases of CPD were diagnosed in labour. A non-engaged head with clinical pelvimetry before onset of labour was also taken as CPD. Bad Obstetric History $(\mathrm{BOH})$, premature rupture of membrane and cases on request also underwent LSCS. $\mathrm{BOH}$ included cases with history of recurrent abortions or a fresh still birth or early neonatal death after a difficult or instrumental delivery. Distribution according to indication of LSCS is shown in Table 4.

Table 5: Distribution of LSCS according to situation.

\begin{tabular}{|lll|} 
Situation & $\begin{array}{l}\text { Number of cases } \\
\text { (n) }\end{array}$ & $\begin{array}{l}\text { Percentage } \\
\text { Elective LSCS }\end{array}$ \\
\hline Emergency LSCS & 1038 & 27.9 \\
\hline
\end{tabular}

In our medical college Emergency caesarean section rate $(72.1 \%)$ is quite high as it is a tertiary care centre so many cases are referred here from periphery and other private hospitals. Elective LSCS was done in $27.9 \%$ cases who were post-dated with an unfavourable cervix and a non-engaged head and were unwilling to go for induction of labour and few of them were infertility treated cases with precious child unwilling to take risk. Distribution of LSCS according to situation is shown in Table 5. Most of LSCS were done in $>38$ weeks period $(68.9 \%)$ followed by 34-38 weeks as shown in Table 6 . Few cases were delivered before 34 weeks due to pre-mature rupture of membrane, abruptio placenta and severe eclampsia.

Table 6: Distribution of patients according to weeks of pregnancy.

\begin{tabular}{|c|c|c|}
\hline Week of pregnancy & $\begin{array}{l}\text { Number of cases } \\
\text { (n) }\end{array}$ & Percentage \\
\hline 32 to $\leq 34$ & 81 & 5.6 \\
\hline$>34$ to $\leq 38$ & 367 & 25.5 \\
\hline$>38-40$ & 992 & 68.9 \\
\hline
\end{tabular}

\section{DISCUSSION}

There has been a steady increase in the rate of caesarean section in both developed and developing countries. Although the WHO recommends that there is no justification to increase caesarean rate in excess of 10 to $15 \%$, it may be difficult to contain the rates in tertiary institutes, catering to a large population of transferred cases. $^{6}$ In present study the maximum number of caesarean sections were done for those with a Previous LSCS which was a significant $35 \%$. No trial of labour for vaginal birth after caesarean section (VBAC) was undertaken in any of the cases of previous LSCS. Many of them were referred cases from nearby hospitals.

After one LSCS there is a $67 \%$ chance of having repeat caesarean delivery. ${ }^{7}$ The low threshold for performing VBAC is probably due to fear of uterine rupture in labour which is 5.2/1000 compared with (1.6/1000) ERCD (elective repeat caesarean delivery) and it can be catastrophic leading to perinatal death (1/1000) and very rarely maternal death. ${ }^{8-10}$ These guidelines were laid down as factors favouring VBAC-if the previous caesarean involved a low transverse incision then there is less risk of uterine rupture; a previous successful vaginal delivery increases the chances of successful VBAC; the indication for previous caesarean section should not be present in the current pregnancy; location at an institute equipped to respond to emergencies.

In a study of 614 cases conducted in Pakistan at Nawaz Sharif social security hospital at Lahore, it showed similar results with Previous LSCS being the most common indication accounting for $56.3 \%$ of cases followed by foetal distress $(17.5 \%) .{ }^{11}$ Similar, study done in Mymensingh medical college showed the most common indication for LSCS was Previous LSCS, followed by foetal distress. ${ }^{12}$

Foetal distress was the next leading indication for performance of a LSCS in the present study. Foetal distress refers to foetal hypoxia, but often no efforts are made to document this condition which would be desirable for medico legal purposes later. Also, a significant rise in caesarean section could be attributed to electronic foetal monitoring. A study by Levens et al. published in the New England journal of medicine confirms, higher caesarean section rates for foetal distress 
with no significant difference in the perinatal mortality rates in the caesarean versus vaginal route of delivery. ${ }^{13}$ 9.4\% patients had breech presentation which was similar to study done by Karim et al. ${ }^{14}$

Patients who were from higher class of socio-economic status or who were graduate and office workers had personal request of getting LSCS done which accounted for $1.3 \%$ because it was feasible and less time consuming and did not wanted to undergo so much trauma and did not want to take any risk. ${ }^{15}$ In India day and time of birth has astrological significance. Through caesarean delivery many parents have their baby at the auspicious moment. For example, Janmastami, Deepawali, New year is such an auspicious day.

In discussing the ethics of medically elective caesareans, the American College of Obstetricians and Gynaecologists states, in the absence of significant data on the risks and benefits of caesarean delivery, if the physician believes that caesarean delivery promotes the overall health and welfare of the woman and her fetus more than vaginal birth, he or she is ethically justified in performing a caesarean delivery.

In contrast, the International Federation of Gynaecology and Obstetric states (at present because hard evidence of net benefit does not exist), performing caesarean section for non - medical reasons is not ethically justified. In 2004, Queenan noted that the underlying question is not the ethics of patient choice, but lack of scientific proof of risks and benefits. ${ }^{16}$ Medically elective caesarean delivery (compared with the combination of planned vaginal and unplanned caesarean delivery) was associated with:

- A decreased risk for maternal haemorrhage

- An increased risk of respiratory problems for infants

- Greater complications in subsequent pregnancies, including uterine rupture and placental implantation problems, and

- $\quad$ Longer maternal hospital stays.

\section{CONCLUSION}

In present study LSCS rate $(31.1 \%)$ was quite high as compared to the WHO standard (5-15\%).

Obstetricians should abide by ethics in clinical practice and carefully evaluate the indication in every CS and take an unbiased decision before performing LSCS on demand/request. Although the debate will continue regarding the appropriateness of LSCS on demand, any discussion of risks and benefits must include the potential for long term risks of repeated LSCS, including hysterectomy and maternal and fetal death. The scheme like Janani Suraksha Yajona (JSY) may have a great impact on accepting institutional deliveries by poor women which may be a reason of the increase of LSCS in India. Among all other factors, perhaps place of delivery (private or public medical institution) is becoming the strongest one influencing LSCS. Unnecessary caesarean delivery also put strain on family and may complicate maternal and child health. Therefore, the decision to perform a C-section delivery must be chosen carefully and should not be profit oriented. Utilization of ANC, better doctor-patient communication, doctor's commitment to reduce the rate of LSCS, government's intention to develop better health care infrastructure and strict vigil on the private health institutions may help to reduce the high and increasing rate of caesarean delivery.

\section{Funding: No funding sources}

Conflict of interest: None declared

Ethical approval: The study was approved by the Institutional Ethics Committee

\section{REFERENCES}

1. World Health Organisation. Monitoring emergency obstetric care: a handbook. Geneva, Switzerland;2009.

2. Althabe F, Belizon JM. LSCS: the paradox. Lancet. 2006;368(9546):1472-3.

3. Van Dongen P. Caesarean section-etymology and early history. South Afr J Obstet Gynaecol. 2009;15(2).

4. Padmadas SS, Kumar S, Nair SB, Kumari A. Caesarean section delivery in Kerala, India: evidence from a National Family Health Survey. Soc Sci Med. 2000;51(4):511-21.

5. NIH State-of-the-Science Conference statement on Caesarean Delivery on Maternal Request - NIH Consens Sci Statements. 2006;23(1):1-29.

6. Oumachigui A. Changing trends in Caesarean Section. Obstet Gynaecol Today. 2002;7:1-5.

7. Thomas J. Royal college of Obstetrician and gynaecologist: Clinical effectiveness and support unit. The Nation Sentinel LSCS Audit report London. RCOG press, 2001.

8. Lydon-Rochelle M, Holt VL, Easterling TR, Martin DP. Risk of uterine Rupture during labour among women with a prior caesarean delivery. $\mathrm{N}$ Engl $\mathrm{J}$ Med. 2001;345:3-8.

9. Mozurkewick EL. Hutt on EK; Elective repeat caesarean delivery versus trial of labour: A metaanalysis of literature from 1989 to 1999 . Am J Obstet Gynecol. 2000;183:1187-97.

10. Rageth JC, Grossenbecher H. Delivery after previous caesarean: A risk evaluation. Swiss working group of Obstetrics and gynaecologic Institutions. Obstet Gynecol. 1999;93:332-7.

11. Rafique S, Rana G. Changing trends in caesarean section rate and indications. Pak $\mathrm{J}$ Surg. 2012;28(1):60-4.

12. Nahar K. Indications of caesarean section: study of 100 cases in Mymensingh medical college hospital. J Shaheed Suhrawardy Med Coll. 2009 Dec;1(1):6-10.

13. Khunpradit S, Patumanond J, Tawichasri C. Risk indicators for cesarean section due to cephalopelvic 
disproportion in Lamphun hospital. J Med Assoc Thailand. 2005 Oct 28;88:S63.

14. Karim F, Ghazi A, Ali T, Aslam R, Afreen U, Farhat R. Trends and determinants of caesarean section. J Surg Pak (International). 2011 Jan;16(1):22-7.

15. Feng $\mathrm{XL}, \mathrm{Xu} \mathrm{L}$, Guo Y, Ronsmans C. Factors influencing rising caesarean section rates in China between 1988 and 2008. Bull World Health Organization. 2012 Jan;90(1):30-9A.
16. Zhang J, Troendle J, Meikle S, Klebanoff MA, Rayburn WF. Isolated oligohydramnios is not associated with adverse perinatal outcomes. BJOG: Int J Obstet Gynaecol. 2004 Mar 1;111(3):220-5.

Cite this article as: Sharma N, Jhanwar A. Study of incidence, trends and determinants of caesarean section in tertiary care hospital of Rajasthan, India. Int J Reprod Contracept Obstet Gynecol 2018;7:2672-6. 